\title{
Educação de jovens e adultos trabalhadores no Brasil atual: do simulacro à emancipação
}

\author{
Sonia Maria Rummert*
}

\section{Resumo:}

A educação dos trabalhadores jovens e adultos, no Brasil atual, vem recebendo especial destaque no âmbito das políticas do governo federal. Para além da aparente "democratização" das oportunidades de elevação de escolaridade e, sobretudo, de acesso às bases do conhecimento científico e tecnológico, tal processo é dotado de funcionalidades que requerem ser desveladas. Com esse objetivo, serão apresentados alguns dos principais condicionantes socioeconômicos das atuais ações governamentais voltadas para a elevação de escolaridade da classe trabalhadora, tomando como referência a atual divisão social do trabalho na sociedade brasileira. Serão abordadas, ainda, as relações que os movimentos sociais estabelecem com essas políticas, que tanto podem se voltar para a busca da emancipação, que se constrói explorando o caráter contraditório do real, quanto estar marcadas pela adesão acrítica e conformadora. Compreender tais processos, em sua complexidade, exige que sejam estabelecidas distinções entre os chamados movimentos sociais "tradicionais" e os "novos movimentos sociais", o que constitui, também, objetivo deste trabalho.

Palavras-chave: Educação de adultos. Educação para o trabalho. Movimentos sociais.

\footnotetext{
* Doutora em Ciências Humanas - Educação, pela PUC-RJ, realizou estudos de pósdoutorado em Formação de Aduitos na Universidade de Lisboa. Professora do Curso de Pedagogia e do Programa de Pós-Graduação em Educação da Universidade Federal Fluminense. Membro do NEDDATE. Pesquisadora do CNPq.
} 


\section{Considerações iniciais}

Pretende-se, neste artigo ${ }^{1}$, apresentar elementos que contribuam para avaliar as atuais políticas de governo voltadas para a educação de jovens e adultos da classe trabalhadora, tendo como horizonte, para o desenvolvimento da crítica a tais políticas, entre outros elementos, o conceito de emancipação, tal como compreendido na perspectiva do materialismo histórico.

Partimos do pressuposto de que as políticas de governo atualmente implementadas no âmbito da educação de jovens e adultos trabalhadores, no Brasil, estão fundadas em estratégias de construção e manutenção da hegemonia que perpetuam, sob diferentes roupagens, as relações fortemente assimétricas de poder, bem como os processos de concentração de riqueza e renda que marcam o País. Tais políticas, portanto, se apresentam como instrumentos de manutenção da ordem instituída e não objetivam a formação integral, concorrendo, como já demonstrado em outros trabalhos (RUMMERT, 2004, 2005, 2006, 2007a e 2007b), para a histórica dualidade estrutural de nossa sociedade.

Configurada no Brasil predominantemente como modalidade de ensino destinada à alfabetização e/ou elevação da escolaridade e, com freqüência, associada à formação profissional, a educação de jovens e adultos inscreve-se num cenário em que são camufladas as razões estruturais dos diferentes processos de destituição de direitos da classe trabalhadora, agora conceitualmente fragmentada em diversos grupos focais, o que obscurece a existência dessa classe como tal. É obscurecido, também, por meio de falsos discursos de universalização de acesso e de democratização de "oportunidades", o direcionamento dos jovens e adultos com pouca ou nenhuma escolarização para diferentes ofertas de elevação de escolaridade que corroboram a atual divisão social do trabalho. Tal processo, apesar de seu desenho contemporâneo, não foge às clássicas estratégias de distribuição desigual e precária de fragmentos de conhecimento, subordinadas às demandas de distintos niveis de qualificação da força de trabalho requeridos pelos diferentes padrões produtivos que coexistem no País, bem como às necessidades de controle social.

Consoante com recentes análises e recomendações do Banco Mundial para os países da América Latina, a educação de jovens e adultos é concebida, 
nas atuais políticas de governo, como o elemento essencial na superação das condições de "exclusão" e de pobreza, tal como recorrentemente anunciado pelos discursos hegemônicos. Sobre essa questão, Filgueiras e Gonçalves (2007, p. 152) observam, com pertinência, que, apesar das inovações, a lógica desse organismo multilateral não altera a matriz explicativa sobre a "[...] origem, a reprodução e a perpetuação da pobreza" A pobreza

[...] decorreria, fundamentalmente, do reduzido acúmulo de "capital humano" por parte dos pobres, especialmente por seu baixo nível de escolaridade. Estamos diante de um círculo vicioso: a baixa escolaridade produz os pobres e a pobreza; esta, por sua vez, impede um maior nível de escolaridade. Por meio desse raciocínio circular, que transforma uma correlação empiricamente observável - baixa escolaridade versus pobreza - em uma relação de causalidade, a estrutura de propriedade e a natureza do modelo econômico existentes não têm importância para explicar a criação e reprodução das desigualdades sociais e da pobreza. (FILGUEIRAS; GONÇALVES, 2007, p. 152).

A circularidade do argumento se constrói na deliberada omissão dos condicionantes estruturais da divisão social do trabalho - nos planos nacional e internacional -, fundados na subordinação e na dominação do trabalho pelo capital. Para desvelá-la, faz-se necessátio apreender a dinâmica contraditória do capital e de sua lógica, visando a superar a percepção dos fenômenos, concebidos como "naturais", para identificar a essência das relações sociais, como tão bem explicitou Kosik (1978). Segue-se, assim, a fundamental indicação de Marx (1983), quando evidencia que o que confere sentido à ciência é o fato de a aparência e a essência dos fenômenos sociais não serem coincidentes, pois, se o fossem, a ciência não se faria necessária à compreensão da realidade.

Ressalta-se, portanto, o fato de que, no âmbito das políticas sociais focalizadas, "[...] que passam ao largo do enfrentamento estrutural da pobreza e da péssima distribuição de riqueza e renda" (FILGUEIRAS; GONÇALVES, 2007, p. 224), a educação de jovens e adultos vem somarse a um conjunto de ações que reforçam as características fundamentais 
do modelo de desenvolvimento desigual e combinado que caracteriza a organização do mundo capitalista.

Outro aspecto a destacar consiste na compreensão de que somente no âmbito das relações sociais podem ser superadas as diferentes formas de subsunção do trabalho ao capital. Nessa perspectiva, é fundamental compreender que tal superação não se dá estritamente no plano material, mas requer transformações no âmbito da cultura-ideologia (GRAMSCI, 1999), entrelaçando os planos da objetividade com os da subjetividade. A educação situa-se, precisamente, na interseção desses dois planos, por constituir, simultaneamente, um bem imaterial e uma ferramenta de trabalho. Tal percepção nos auxilia a compreender os sentidos da distribuição desigual dos conhecimentos num sistema socioeconômico que objetiva naturalizar pelo mérito e controlar pelo simbólico as fortes assimetrias de poder em que se assenta.

Também não pode ser ignorado o fato de que todos os mecanismos materiais e simbólicos de dominação são geradores de tensões sociais que se expressam em diferentes processos de correlações de forças (GRAMSCI, 2000), os quais indicam o quanto uma classe ou fração de classe constitui ou pode vir a constituir uma força social. Isto é, a análise das correlações de forças - em particular, seu momento político (GRAMSCI, 2000) - nos permite identificar as reais potencialidades de uma classe ou fração de classe se organizar e consolidar posições nas lutas por seus direitos e nas disputas por hegemonia. Não é outra a razão pela qual as forças dominantes se valem, permanentemente, de estratégias de conformação à ordem e de captura das aspirações e reivindicações da classe trabalhadora, muitas vezes organizativas de movimentos sociais, com o fito de manter em níveis satisfatórios a situação de controle social. Nesse sentido, a educação e a escola ocupam papel fundamental no permanente processo de construção e manutenção da hegemonia (GRAMSCI, 1999).

\section{A funcionalidade da elevação de escolaridade de jovens e adultos trabalhadores na atual divisão social do trabalho na sociedade brasileira}

Para compreendermos a educação de jovens e adultos trabalhadores, em sua atual configuração, faz-se necessário tomá-la em sua historicidade, 
relacionando-a aos determinantes socioeconômicos que a condicionam. A partir do ciclo econômico iniciado na década de 1930 e que tomou corpo a partir dos anos 1950, adquire forma o processo de industrialização, cuja matriz cultural assentava-se em três pontos centrais: o fetiche do progresso e do desenvolvimento de cariz conservador, a ênfase na virtuosidade do trabalho sob os moldes da lógica capitalista e a promessa de ascensão social pela via da educação. Esses traços vieram se somar à marca escravocrata, ao patrimonialismo e ao autoritarismo herdados dos tempos coloniais e, ainda, às práticas populistas.

A essa bagagem histórica, somam-se, a partir dos anos 1990, as transformações relativas aos novos padrões de acumulação, o que repercutirá de forma intensa na constituição da classe trabalhadora. Para os fins deste trabalho, basta registrar o fato de que desse intrincado processo contraditório e multiforme, decorreu a "heterogeneização, fragmentação e complexificação da classe trabalhadora" (ANTUNES, 1995, p. 16), devido à qualitativa transformação da forma de ser do trabalho que, por um lado, apresenta fortes demandas de maior qualificação e, de outro, relega a maior parte dos trabalhadores a ocupações que demandam baixos níveis de conhecimento (RUMMERT, 2000, p. 65).

Assim, do novo conteúdo nacional e internacional de divisão do trabalho e dos novos padrões de produção e acumulação aos quais o País se subordina ao perseguir o fetiche da competitividade, emergem vetores que reorganizam todas as dimensões da existência.

Passamos, assim, de um modelo societário paternalista, que poderia ser representado pela imagem da company town, da qual a cidade de Volta Redonda constituiu o exemplo paradigmático no Brasil, para um padrão de sociabilidade marcado pela imposição da (des)ordem pela volatilidade do mercado como único mecanismo regulador viável das relações socioeconômicas fundadas na degradação dos direitos sociais, em novas formas de concentração da riqueza, na distribuição diferencial do conhecimento e no aprofundamento das condições de precarização do trabalho, sempre presentes de modo acentuado no Brasil, embora assumindo formas diferenciadas. ${ }^{2}$

Transformada em moeda de troca, a educação, nesse quadro, passa a constituir reclamo comum às forças dominantes e às diferentes frações da classe trabalhadora, do mesmo modo que se faz recorrentemente presente nas recomendações dos organismos internacionais de financiamento, os 
quais enfatizam a importância de que os países periféricos e semiperiféricos (ARRIGHI, 1997) dediquem atenção à ampliação do acesso à educação básica e à elevação da escolaridade da classe trabalhadora.

Uma vez que a simples negação do direito à educação deixa de ser funcional às novas exigências do padrão de acumulação, e não sendo, também, mais sustentável em termos de construção e manutenção da hegemonia, surgem novas estratégias de perpetuação da dualidade no âmbito educacional. Especificamente no que se refere à elevação da escolaridade dos jovens e adultos trabalhadores, surge no País na década atual, mais precisamente a partir de 2003, uma variedade de ofertas de oportunidades de certificação que correspondem, no mais das vezes, a simulacros de ações educativas.

Esse quadro, coerente com o fato de que o Brasil se inscreve na divisão internacional do trabalho como lócus de "[...] transferência e cópia de ciência e tecnologia e não pela sua produção" (FRIGOTTO, 2006, p. 262), permite compreender o aparente paradoxo contido no duplo movimento de valorização discursiva da educação geral e de qualidade para todos, e o concomitante processo social de concentração do conhecimento (RUMMERT, 1995; 2000). Essa perspectiva exige que, para compreendermos o real sentido hoje conferido à educação da classe trabalhadora brasileira, não seja ignorada "[...] nossa posição na divisão internacional do trabalho e a conseqüente supremacia do investimento na reprodução do trabalho simples" (FRIGOTTO, 2006, p. 262).

A distinção entre trabalho complexo e trabalho simples, como assinalado por Frigotto, constitui fundamento da divisão internacional de trabalho entre os países situados no núcleo orgânico e aqueles que constituem a periferia e a semiperiferia do sistema do capital, atribuindo aos primeiros o monopólio do trabalho complexo, particularmente no que tange à pesquisa e à alta tecnologia, procurando circunscrever os demais países a diferentes situações de executores do trabalho simples.

Já em Adam Smith está explicitada a diferença entre o trabalho mais complexo ou qualificado e o trabalho simples, sem maior qualificação. Será, entretanto, Marx quem clarificará tal distinção entre o que denomina trabalho simples ou trabalho social médio e trabalho complexo, potenciado ou qualificado: 
Trabalho humano mede-se pelo dispêndio da força de trabalho simples, a qual, em média, todo homem comum, sem educação especial, possui em seu organismo. O trabalbo simples médio muda de caráter com os países e estágios da civilização, mas é dado numa determinada sociedade. Trabalho complexo ou qualificado vale como trabalho simples potenciado ou, antes, multiplicado, dado que uma determinada quantidade de trabalho qualificado é igual a uma quantidade maior de trabalho simples. (MARX, 1980, p. 51 , grifos do autor) ${ }^{3}$

Tanto o trabalho simples quanto o complexo agregam valor à mercadoria durante o processo de produção, mas não na mesma proporção: uma hora de trabalho complexo cria mais valor que uma hora de trabalho simples, uma vez que uma das marcas do trabalho complexo reside no custo social da qualificação que sua execução demanda. Isto transparece nos preços praticados no comércio exterior, constituindo elemento essencial à troca desigual, um dos pilares do desenvolvimento desigual e combinado.

É importante, ainda, assinalar que todo trabalho complexo pode ser divisível em múltiplas quantidades de trabalho simples, e que a distinção entre ambos se vincula à qualificação necessária ou supostamente necessária à sua execução. Ou seja, há uma telação direta entre o valor do trabalho complexo e o tempo socialmente gasto para a preparação de seu executor. Ainda segundo Marx (1980), a redução do trabalho complexo para trabalho simples constitui uma tendência concreta do capitalismo.

Tal processo pode ser explicitado em análises de Kuenzer (2007), que, tomando como referência suas pesquisas na cadeia produtiva coureirocalçadista, ressalta que, coadunados com a lógica da flexibilização do trabalho, pilar do padrão de acumulação flexível, os processos produtivos buscam manter ou ampliar a margem de acumulação, visando à competitividade, a partir de um processo combinado de implantação da automação e da intensificação do consumo do trabalho humano.

Segundo a autora, na cadeia pesquisada, “[...] esta estratégia é clara; não há automação que supere o baixo custo do trabalho que combina os ateliês (oficinas), o trabalho domiciliar feito pelas costureiras e a rede 
de trabalhadores manuais desqualificados" (KUENZER, 2007, p. 13). A análise evidencia que as "[...] relações de trabalho que se supunham superadas através do processo civilizatório do capital retornam como estratégias essenciais ao processo de acumulação, combinadas com relações mais contemporâneas mediadas pela ciência e a tecnologia, através da flexibilização" (KUENZER, 2007, p. 14).

A análise do setor, tal como apresentada por Kuenzer, permite estabelecer analogias entre as formas de relação de trabalho construídas no âmbito da lógica capitalista na atualidade e aquelas vigentes na segunda metade do século XIX. Sem ignorar o fato de que, como assinalou Marx (1980), já citado, o caráter do trabalho simples médio se altera em diferentes países e distintos estágios da civilização, podemos nos reportar aos estudos de Hobsbawm sobre a época da Revolução Industrial, quando os empregadores britânicos utilizavam diferentes estratégias para disciplinar os trabalhadores. Uma delas consistia em "[...] sempre que possível, [...] pagar tão pouco ao operário que ele tivesse que trabalhar incansavelmente durante toda a semana para obter uma renda mínima" (HOBSBAWM, 1989, p. 67). Outra forma corrente na época "[...] era o subcontrato ou prática de fazer dos trabalhadores qualificados os verdadeiros empregadores de auxiliares sem experiência" (HOBSBAWM, 1989, p. 67). Tal prática verificava-se no interior da fábrica, $\mathrm{e}$ "[...] fora das fábricas propriamente ditas tais acordos eram ainda mais comuns" (HOBSBAWM, 1989, p. 67). O subempregador, é claro, "[...] tinha um incentivo financeiro direto para que seus auxiliares contratados não se distraíssem" (HOBSBAWM, 1989, p. 67). Não é difícil identificar, na atualidade, práticas análogas às aqui descritas nos processos de terceirização do trabalho, tal como se verifica em diferentes cadeias produtivas.

Ao analisar, ainda no início da década de 1990, a reestruturação pósfordista e a reorganização dos processos de trabalho dela advindas, Castro apresenta uma categorização da classe trabalhadora formulada por Standing, a qual, por fugir às dicotomias comuns "[...] protegidos/desprotegidos, formal/informal, centro/periferia" (CASTRO, 1994, p. 44), parece a Castro mais adequada à análise. Segundo ela, a população economicamente ativa dos países europeus podia ser dividida em cinco grupos principais. Os dois primeiros, integrados ao núcleo central da produção, de setores internacionalizados ou nacionais, ligados à gestão ou às novas tecnologias, 
com elevado grau de escolaridade, usufruindo de graus de proteção significativos (CASTRO, 1994, p. 44). Já o terceiro grupo

[...] está formado por trabalhadores manuais de setores declinantes, com força de trabalho excedente, obrigados a negociar concessões para defender $o$ emprego. O quarto grupo, o que mais cresce, reúne trabalhadores de serviços com baixa produtividade, com mão-de-obra excedente, salários declinantes, proteção mínima e péssimas condições de trabalho. $O$ quinto e último grupo está formado pelos excluídos do mercado de trabalho: jovens e mulheres à procura do primeiro emprego, trabalhadores desanimados por longos períodos de desemprego ou inatividade provocada por doenças, acidentes, alcoolismo ou droga. Este grupo cresce em número e sua situação social decai (CASTRO, 1994, p. 44-45).

Para Castro (1994, p. 45), tal classificação, que constitui um "[...] resumo eloqüente do atual quadro social do pós-fordismo do 'primeiro mundo', pode servir de referência para a análise dos custos sociais do reajuste neoliberal aplicado nos capitalismos periféricos".

Embora ainda se verifique a ausência de uma categorização que contemple, de modo específico, a realidade brasileira, entendemos, como Castro, que os grupos acima tipificados correspondem a uma parcela significativa da população economicamente ativa do Brasil e, também, que o quarto e o quinto grupos correspondem aos focos preferenciais das ofertas de acesso à elevação de escolaridade associada à formação profissional nos programas atualmente implementados pelo governo federal, entre os quais merece destaque, por suas características marcadamente assistencialistas, por exemplo, o Programa Nacional de Inclusão de Jovens: Educação, Qualificação e Ação Comunitária - PROJOVEM, já abordado em outros trabalhos e o Programa Nacional de Integração da Educação Profissional com a Educação Básica na Modalidade de Educação de Jovens e Adultos - PROEJA (RUMMERT, 2007b).

No caso especifico do PROJOVEM, conforme estudo anterior, previa-se oferecer, em um ano, os conhecimentos necessários à conclusão do Ensino Fundamental e à formação profissional, além de atividades 
denominadas como ações comunitárias. Embora não seja possível, aqui, analisar a real viabilidade pedagógica de tal proposta, é perceptivel o fato de que tais objetivos não podem ser alcançados de modo a assegurar aos que participam do Programa um efetivo acesso às bases do conhecimento científico e tecnológico, sobretudo ao verificarmos que a organização curricular do Programa reserva apenas duas horas de aula semanais para o estudo da Língua Portuguesa, duas para Língua Estrangeira e, ainda, a mesma carga horátia para Matemática, Ciências Humanas e Ciências da Natureza. As outras três horas de cada dia são ocupadas com Formação Profissional, noções de Informática e Ação Comunitária (RUMMERT, 2007b).

Em setembro de 2007, foi lançado pelo governo federal o novo PROJOVEM, agora com a duração de 18 meses, “[...] um programa unificado de juventude para ampliar o atendimento aos que estão fora da escola e excluídos dos cursos de formação profissional" (BRASIL, 2007c), sendo aprovada, pelo Congresso, a respectiva Medida Provisória 411/07, que reformulou o Programa de Inclusão de Jovens e ampliou os benefícios do Programa Bolsa-Família. Segundo a Radiobrás, o Programa ampliou a faixa etária dos beneficiários para até 29 anos. Ainda de acordo com a mesma fonte, a coordenação fica a cargo da Secretaria-Geral da Presidência da República, que contará com um colegiado "[...] formado por membros dos três ministérios envolvidos no PROJOVEM: Desenvolvimento Social e Combate à Fome; Educação; Trabalho e Emprego". O novo desenho do PROJOVEM "[...] nasceu da unificação de cinco programas já existentes (Agente Jovem; Saberes da Terra; PROJOVEM; Juventude Cidadã e Escola de Fábrica) e resultou em quatro subdivisões: PROJOVEM Urbano, PROJOVEM Campo, PROJOVEM Trabalhador e PROJOVEM Adolescente". É importante assinalar, para os fins de argumentação deste trabalho, que a formação profissional, de caráter inicial, abriga, por exemplo, as seguintes atividades: auxiliar de produção cultural, ladrilheiro, cozinheiro, almoxarife, pintor, eletricista, instalador de linhas e aparelhos de telecomunicações, guias de turismo, recepcionistas de hotel, operador de computador, monitor de esporte e lazer, costureiro, fotógrafo, joalheiro [trabalho com bijuterias] e caseiro. Uma característica peculiar do Programa reside no fato de que os responsáveis por sua formulação e implementação não o reconhecem como uma iniciativa no âmbito da Educação de Jovens e Adultos, embora esteja estruturado sob a forma 
escolar; funcione, prioritariamente, em escolas da rede pública; valha-se de instrumentos nacionais de avaliação e certifique ao nível de conclusão do Ensino Fundamental. Deve-se chamar a atenção, ainda, para o fato de que, nos documentos oficiais, é estabelecida a meta de 4,2 milhões de vagas até o ano 2010.

Outro programa destacado, o PROEJA, apresenta perfil inteiramente distinto do PROJOVEM, evidenciando o fato de destinar-se a outra fração da classe trabalhadora. Situado no âmbito da modalidade Educação de Jovens e Adultos, e concebido e executado pelo Ministério da Educação, sob a responsabilidade da Secretaria de Educação Profissional e Tecnológica, está aberto a pessoas com idade mínima de 18 anos, sem limite máximo estabelecido. A oferta abrange três níveis:

- educação profissional técnica de nível médio com Ensino Médio, destinado a quem já concluiu o Ensino Fundamental e ainda não possui o Ensino Médio, e pretende adquirir o título de técnico;

- formação inicial e continuada com o Ensino Médio, destinado a quem já concluiu o Ensino Fundamental e ainda não possui o Ensino Médio, e pretende adquirir uma formação profissional mais rápida;

- formação inicial e continuada com Ensino Fundamental, para aqueles que já concluíram a primeira fase deste ensino.

Dependendo da necessidade regional de formação profissional, são, também, admitidos cursos de formação inicial e continuada com o Ensino Médio (BRASIL, 2007b). Quanto à carga horária, ainda segundo o Decreto 5.840/2006, os cursos destinados à Formação Inicial e Continuada deverão contar com carga horária mínima de mil e quatrocentas horas, assegurandose, cumulativamente: a destinação de, no mínimo, mil e duzentas horas para formação geral e a destinação de, no mínimo, duzentas horas para a formação profissional. Já os cursos de Educação Profissional técnica de nível médio deverão contar com carga horária mínima de duas mil e quatrocentas horas, assegurando-se, cumulativamente: a destinação de, no mínimo, mil e duzentas horas para a formação geral; a carga horária mínima estabelecida para a respectiva habilitação profissional técnica; bem como a observância às diretrizes curriculares nacionais e demais atos normativos do Conselho Nacional de Educação para a Educação Profissional técnica 
de nível médio, para o Ensino Fundamental, para o Ensino Médio e para a Educação de Jovens e Adultos.

O MEC registra um total de 147 cursos em andamento no periodo de 2006 a 2010, oferecidos, predominantemente, pelos Centros Federais de Educação Tecnológica em 18 Estados da Federação. Tais cursos concentramse, principalmente, nas seguintes áreas profissionais: agropecuária, comércio, construção civil, informática, indústria, saúde, e turismo e hospitalidade. Deve-se assinalar, ainda, que o Programa inclui um significativo aporte de apoio, contando com cursos de especialização para formação de professores e, ainda, com financiamento para a realização de pesquisas e para bolsas de mestrado e doutorado oferecidas para pesquisadores que se proponham a empreender investigações no âmbito do Programa. Em que pese, porém, todo o arcabouço do Programa, inédito no âmbito da Educação de Jovens e Adultos no Brasil, sua divulgação é incipiente, o que concorre, segundo a avaliação de vários coordenadores, para a o baixo índice de matrículas. Tal fato faz com que, atualmente, segundo dados por nós levantados junto aos mesmos coordenadores, o PROEJA registre o atendimento a apenas 8 mil pessoas em todo o País.

Com as considerações acima apresentadas, pretendemos ilustrar a fragmentação da Educação de Jovens e Adultos no Brasil, a qual, segundo nosso entendimento, se organiza de modo a atender, de formas distintas, a diferentes frações da classe trabalhadora, segundo os requerimentos do sistema produtivo e as necessidades de controle social. Entendemos, também, trazer aspectos que podem levar a questionamentos acerca da expressão "apagão da mão-de-obra", já corrente para referir-se à anunciada falta de profissionais qualificados para ocupar os postos de trabalho disponíveis no País, como insistentemente apresentado pela mídia no último ano, mas que não podem ser abordados nos limites deste trabalho.

Ao nos determos na educação dos jovens e adultos trabalhadores tal como se configura, atualmente, no Brasil, tomando-a em sua historicidade, podemos desvelar a lógica que se oculta nas propostas de democratização das possibilidades de acesso ao conhecimento. Na realidade, não se verifica nenhuma intencionalidade de atingir linearmente toda a classe trabalhadora com um padrão igualitário e elevado de educação. Ao contrário, a regulação diferenciada da distribuição de condições de acesso aos bens materiais e imateriais - entre os quais, a educação - pelas forças dominantes não 
se ancora em critérios de igualdade, mas na "desigualdade substantiva" (MÉSZÁROS, 2002) e na difusão da crença na possibilidade individual de superá-la, como elemento essencial do desenvolvimento, da modernização e da competitividade.

Esse processo, que, na essência, não constitui um fato novo, foi claramente explicitado por Hobsbawm (1989), quando destaca que a Inglaterra, berço da Revolução Industrial, não precisou de mais do que uns poucos especialistas para desencadear o processo. Mais do que capacitar tecnicamente a massa de trabalhadores que acorreu às cidades em virtude da miséria que se alastrava pelo campo, o essencial era adaptá-la ao espaço, ao tempo, ao ritmo e às normas do trabalho fabril.

Também hoje, quando os novos padrões de acumulação permitem, em parte, prescindir de grandes massas humanas envolvidas diretamente na produção, as ações educativas têm como uma de suas funções principais, junto às frações mais destituídas de direitos da classe trabalhadora, a tarefa de conformar, visando a assegurar as condições básicas de controle social. Como assinala Puiggrós (2004, p. 26), a vida dos jovens e adultos dessas frações de classe está submetida "[...] a un capitalismo salvaje que la desprecia y no necesita que adquieran saberes socialmente productivos, excepto los referidos a la seguridad de los demás sectores sociales". Ao analisar as ações focais destinadas aos grupos tidos como em maior risco social, na América Latina, ao final da década de 1990, afirma, ainda, a autora que algumas alterações foram introduzidas pelas políticas neoliberais, as quais, entretanto, não objetivavam

[...] la reinserción del conjunto de los marginados del sector productivo y de los SSP [saberes socialmente produtivos] actualizados, sino su dotación parcial, limitada a lo indispensable para evitar la constitución de los grupos más vulnerables en emergentes contra el poder establecido. (PUIGGRÓS, 2004, p. 26).

A subordinação das ações empreendidas no âmbito da educação de jovens e adultos trabalhadores às estratégias de permanente construção $\mathrm{e}$ manutenção de hegemonia, por parte das forças dominantes, evidencia o fato de que estas não são concebidas a partir da perspectiva de concorrer para a emancipação bumana. Também nos leva a formular questionamentos acerca 
das relações estabelecidas, hoje, entre os movimentos sociais ("tradicionais" e "novos") e as políticas de governo, tal como até aqui enunciado. Nessa perspectiva, com o intuito de oferecer elementos que contribuam para a compreensão de tais processos, se faz necessário apreender as relações entre tais movimentos e as organizações não governamentais (ONGs), que ocupam papel de destaque nas estratégias de controle social, quando se verifica o recuo do Estado no que concerne às responsabilidades no âmbito dos direitos sociais, como abordaremos a seguir.

\section{O controle da desigualdade substantiva em oposição à eman- cipação humana}

Ao tratarmos da temática da emancipação, é necessário sublinhar, inicialmente, que suas diferentes formas de apropriação, a partir de distintos fundamentos político-ideológicos, conferem ao conceito um caráter polissêmico e saturado de significados, muitas vezes subordinados às intencionalidades conservadoras da lógica dominante.

Em decorrência, é preciso referir, ainda que de forma breve, às bases da concepção de emancipação na perspectiva do materialismo histórico, detendo-nos, particularmente, nas reflexões de Marx. Para tanto, devemos nos remeter à distinção que Marx estabelece, em uma de suas primeiras obras, $A$ questão judaica (MARX, 1989), entre a emancipação política e emancipação humana. A primeira, apesar de constituir, segundo ele, um avanço, vincula-se estritamente aos direitos civis, estando circunscrita à sociedade burguesa; já a emancipação humana requer que os homens se reconheçam, para além de suas individualidades, como forças sociais aptas a promover mudanças estruturais na sociedade. Assim, para Marx (1989), ao abordarmos o tema, é fundamental indagar de que tipo de emancipação se trata.

A emancipação humana pressupõe a superação dos múltiplos obstáculos impostos à vida individual e coletiva pela alienação do trabalho no modo de produção capitalista. Como construção comum a todos, a emancipação humana se caracteriza pela imposição do controle do homem coletivo sobre as condições sociais de produção da existência. Tal forma de emancipação pressupõe, portanto, o envolvimento ativo dos sujeitos individuais e coletivos, uma vez que não é construída exteriormente. Ao 
contrário, são os próprios homens, individual e coletivamente, que se autoemancipam.

Para Marx (1989, p. 63, grifos do autor),

A emancipação humana só será plena quando o homem real e individual tiver em si o cidadão abstracto; quando como homem individual, na sua vida empirica, no trabalho e nas relações individuais, se tiver tornado um ser genérico; e quando tiver reconhecido e organizado as suas próprias forças (forces própres) como forças sociais, de maneira a nunca mais separar de si esta força social como força polititica.

Essa perspectiva de emancipação humana, que se opõe radicalmente a qualquer forma de heteronomia, se afasta substantivamente das perspectivas norteadoras das ações empreendidas no âmbito da educação de jovens e adultos, assim como anteriormente referidas. $\mathrm{Na}$ realidade, tais ações constituem expressão das " [...] concretas e imensas dificuldades que a atual organização do mundo impõe aos processos de emancipação, posto que tal organização, apesar de toda retórica em contrário, está fortemente ancorada na heteronomia" (ADORNO, 1995, p. 181).

Corroborando a visão aqui apresentada, encontramos em Mészáros (2007) uma rica análise das marcas da educação, tal como se configura nas sociedades fundadas nas assimetrias de poder e nos processos de exploração dos homens pelos homens:

Quer os indivíduos participem ou não - por mais ou menos tempo, mas sempre por um número de anos bastante limitado - das instituições formais de educação, eles devem ser induzidos a uma aceitação ativa (mais ou menos resignada) dos princípios reprodutivos orientadores dominantes na própria sociedade, adequados a sua posição na ordem social e de acordo com as tarefas reprodutivas que Ihes foram atribuídas. (MÉSZÁROS, 2007, p. 206).

Sob a égide do capitalismo, os trabalhadores, mesmo que não sejam - ou sejam pouco - escolarizados, conforme também assinala Mészátos (2007, p. 206), “[...] ao internalizar as onipresentes pressões externas" 
adotam, do mesmo modo, “[...] as perspectivas globais da sociedade mercantilizada como inquestionáveis limites individuais a suas aspirações sociais" (MÉSZÁROS, 2007, p. 206). Para o pensador húngaro, "Apenas a mais consciente das açôes coletivas poderá livrá-los dessa grave e paralisante situação" (MÉSZÁROS, 2007, p. 206, grifo do autor).

Nos últimos anos, particularmente a partir de 2003, verifica-se uma ampliação da oferta de possibilidades de acesso a programas voltados para a educação de jovens e adultos - básica e profissional -, que se reveste de um caráter de democratização de simulacros de educação. Tal ampliação de oportunidades circunscreve-se a uma ação pedagógica que difunde uma máxima disciplinadora: a imposição da permanente busca individual por qualificação para assegurar o ingresso num mercado de trabalho cada vez mais restritivo e marcado por diferentes condições de precarização revestidas por uma aparência de liberdade que valoriza o empreendedorismo, o auto-emprego, a capacidade de adaptação às regras da flexibilização e da informalidade.

A democratização dos simulacros de educação opera, assim, no plano simbólico, promovendo, a partir da pedagogia da conformação, o “[...] consentimento ativo dos governados" (GRAMSCI, 1999) e a internalização dos limites individuais inerentes às tarefas reprodutivas - como evidenciado por Mészáros (2007), tal como se configuram na atual fase de expansão e consolidação do capital e consoantes com a situação de subordinação do País ao quadro hegemônico internacional.

A força argumentativa da valorização das teses da Teoria do Capital Humano, ressignificadas à luz da hegemonia do ideário neoliberal, permeou, desde a última década do século passado, todas as instâncias do Estado aqui compreendido a partir da teoria ampliada de Gramsci (1999; 2000), em particular no âmbito da sociedade civil. Tal processo repercutiu de modo significativo nos movimentos sociais, cujas origens estão historicamente imbricadas nas formas de organização da classe trabalhadora, influenciando, sobremaneira, as ações desenvolvidas por tais movimentos no âmbito da educação de suas próprias bases, como se evidencia, por exemplo, no movimento sindical (RUMMERT, 2000, 2005). Em decorrência, o Brasil vivenciou uma expressiva ampliação do quadro de atores sociais que assumiram, desde então, tarefas relativas à educação da classe trabalhadora, predominantemente circunscritas a concepções e práticas que concorrem 
para que "[...] a lógica do capital permaneça intacta como quadro de referências orientador da sociedade" (MÉSZÁROS, 2007, p. 207).

Nesse quadro, que nos limites deste trabalho só pode ser brevemente delineado, emerge uma rede de relações entre movimentos sociais, Estado e entidades que integram o denominado Terceiro Setor, reunidos em torno da educação de jovens e adultos trabalhadores. As ações relativas a essa educação se apresentam, nas duas últimas décadas e com cada vez maior intensidade, coadunadas com as novas formas de sociabilidade requeridas pelo capital à classe trabalhadora. Não é demais assinalar que as iniciativas educacionais aqui referidas estão circunscritas ao âmbito do trabalho simples e trazem claras marcas de uma regulação comprometida com o apassivamento e o controle social, tal como já assinalado.

Esse processo, em si revestido de grande complexidade, se torna mais intrincado quando consideramos a emergência, principalmente a partir do final da década de 1990 , dos chamados novos movimentos sociais ${ }^{4}$ no Brasil. Tal emergência, induzida, sobretudo, pelas forças dominantes e às quais se agrega, encontrou espaço de significativa ampliação em decorrência da luta latente pelos meios de vida que foi individualizada e fragmentada, de modo que as forças aglutinadoras de caráter contra-hegemônico perdessem seu poder de convocação e mobilização.

Em aparente oposição ao Estado (Primeiro Setor), cuja ineficiência e potencialidade para a malversação dos recursos públicos são insistentemente alardeadas pelo que muitos autores denominam como o quarto poder: a mídia, e ao mercado (Segundo Setor), impossibilitado de atender às demandas sociais, posto que, por sua natureza, deve perseguir permanentemente o lucro, emerge o Terceiro Setor - termo cunhado, nos Estados Unidos, por Rockfeller III, ao final dos anos 1970 - supostamente, imune às mazelas que caracterizam os tradicionais setores da sociedade e ao qual é conferido um caráter salvacionista.

A análise do Terceiro Setor não pode prescindir do reconhecimento de seu " [...] papel central no processo de desregulação e (contra)reforma estatal, na reestruturação produtiva, na flexibilização produtiva e comercial, no financiamento ao capital, particularmente financeiro" (MONTAÑO, 2002 , p. 17). Na realidade, como assinala o mesmo autor, as entidades que integram o Terceiro Setor apresentam clara funcionalidade ao atual padrão de acumulação, propiciando 
[...] a diminuição dos custos da atividade social - não pela maior eficiência dessas entidades, mas pela verdadeira precarização, focalização e localização destes serviços, pela perda de suas dimensões de universalidade, de não contratualidade e de direito do cidadão - desonerando o capital. (MONTAÑO, 2002, p. 47).

Integram o Terceiro Setor, entre outras, organizações da sociedade civil de interesse público (OSCIPs), organizações sem fins lucrativos, entidades filantrópicas ou assistencialistas, fundações e institutos empresariais, entidades de assistência social privadas sem fins lucrativos ${ }^{5} \mathrm{e}$ as organizações não governamentais (ONGs) ${ }^{6}$, termo que passou a ser utilizado, a partir da década de 1940, pela ONU para designar as entidades que desenvolviam projetos considerados humanitários ou de interesse público, sobre as quais nos deteremos aqui.

Buarque e Vainsencher (2001), em artigo que defende a atuação e a forma de inserção das ONGs no Brasil, destacam que estas, atualmente, fazem parte dos novos movimentos sociais e apresentam características tais como:

[...] alojar-se, política e tecnicamente, como inovadoras do fazer social, alargando o espaço de intervenção popular; dedicar-se à superação dos mecanismos de exclusão sócio-política, ao trabalhar, localmente, o cotidiano de segmentos específicos da população; não representar qualquer classe de indivíduos sendo, por isso, flexíveis e constituir-se em entidades de Direito Privado que concebem a sua ação como sendo pública. (BUARQUE; VAINSENCHER, 2001).

A relação entre os novos movimentos sociais, que assumem destaque, no Brasil, a partir da década de 1990, e as ONGs, tal como acima apresentado, vem constituindo objeto de análise de autores como Petras e Leher, cujos trabalhos evidenciam o fato de que a atuação predominante dessas entidades obscurece a conformidade conservadora em que se assentam, movendo-se no plano fenomênico do mundo político de modo a assegurar a permanência da estrutura do modelo socioeconômico. Assim, a centralidade da questão 
das classes sociais é substituída por temas como a exclusão e a pobreza, a discriminação racial, as questões de gênero, entre outros, abandonando "a perspectiva anti-sistêmica" (LEHER; SETÚBAL, 2005a, p. 30).

$\mathrm{O}$ entrelaçamento do Terceiro Setor com os novos movimentos sociais constitui elemento fundamental das atuais condições de governabilidade. Nessa perspectiva, o que predomina são a captura e o disciplinamento das potencialidades de organização coletiva que objetivem, real ou potencialmente, a transformação estrutural, derivada do pedagógico processo de construção da emancipação humana.

É nesse quadro que podemos, grosso modo, apresentar um esboço de tipificação das ONGs no Brasil, ressalvando tanto o caráter generalizador de qualquer classificação como o fato de que, em muito casos, as características de um tipo se apresentam, em maior ou menor grau, também presentes em outros?.

Além das ONGs estrangeiras, com forte presença principalmente na Amazônia e que, sob a aparência da ação "desinteressada", no âmbito da pesquisa e do ativismo ambiental, agem de acordo com os mais diversos interesses comerciais e neocoloniais de empresas e governos estrangeiros, constituindo sério risco à soberania nacional, podemos identificar quatro tipos principais de ONGs em atuação no País.

As que foram criadas especificamente para captar recursos públicos, corroborando as estruturas de dominação numa perspectiva claramente metcadológica que caracteriza tanto a eleição de grupos focais mais rentáveis quanto a forma como atuam junto a eles. Também é marcante a presença das organizações criadas pelo próprio empresariado, geralmente nas regiões em que se encontram fisicamente localizadas as empresas, visando à renúncia fiscal, às estratégias de marketing social, à preservação de seu patrimônio em decorrência das relações assistencialistas que estabelecem com a população local, reforçadas pelo exercício das práticas de controle social. Com significativa presença no Brasil, temos, ainda, as ONGs que apresentam vinculações diretas com partidos políticos e com seus representantes eleitos para cargos nos Poderes Executivo e Legislativo, cujo perfil apresenta clara função de moeda de troca, posto que os vinculados diretamente a ONGs dispõem de expressivas oportunidades de angariar votos, para si ou para aqueles a quem apóiam, em suas localidades de atuação, como também, ao ocuparem cargos eletivos, tanto têm acesso a mecanismos facilitados para 
transferência de recursos como ampliam a base eleitoral a partir das ações assistencialistas.

Finalmente, devemos mencionar um quarto grupo de ONGs, algumas cujas origens históricas antecedem o período da ditadura militar e outras que, criadas a partir dos anos 1970 , tiveram significativo papel em ações de resistência. Se, por um lado, não pode ser ignorada a importância de sua atuação no âmbito da resistência e na forma de relacionamento com os movimentos sociais de então, por outro, não se pode ignorar o fato de que, a partir da década de 1990, veio a prevalecer a adoção de um modelo de intervenção em muitos e significativos aspectos assemelhado às demais práticas assistencialistas já mencionadas. Tal deslocamento do modelo de intervenção, tornando-o mais ajustado às práticas reformistasconservadoras, deriva, substantivamente, da subordinação à lógica dos financiamentos que asseguram sua sobrevivência institucional. Também em nome da sobrevivência, essas ONGs abandonam os princípios relativos aos direitos do trabalho e assumem um modelo de funcionamento que espelha a lógica do padrão de acumulação flexível, apresentando um traço comum com as demais: as formas de precarização do trabalho em suas práticas de contratação de serviços, valendo-se de expedientes como os da terceirização e dos contratos temporários, entre outros, estabelecendo, assim, distinções abissais entre genéricos discursos em defesa de direitos e suas próprias práticas.

$\mathrm{Na}$ última década, principalmente, a facilidade de obtenção de recursos criou uma espécie de euforia na sociedade, derivada, em alguns casos, da crença de que as ONGs constituíam o espaço virtuoso de expressão e atendimento de demandas pontuais e imediatas da população carente, pobre ou excluida, como normalmente são denominados, a partir de perspectivas assistencialistas, aqueles que são destituídos de seus direitos pelo modelo socioeconômico. Tal euforia social se agravou, obliterando a crítica, pelo fato de que tais instituições passaram, apesar das estratégias de precarização contratuais, a constituir espaço significativo de trabalho, numa sociedade em que os direitos sociais foram transformados em mercadorias.

Sobre tal aspecto, nos limites deste trabalho, consideramos suficiente reproduzir a afirmação de Campagnac, quando, ao tratar das relações entre o mercado de trabalho e a multiplicação de ONGs no País, afirma, naturalizando a questão: 
[...] independentemente do papel dessas organizações - se são efetivas ou não, se promovem bemestar social ou não, se possuem parcerias legítimas ou não - elas servem, em última instância, de força de atração de mão-de-obra contribuindo para uma parcela significativa da geração de recursos nacionais de capital humano no Brasil. (CAMPAGNAC, 2006, p. 21).

Não é demais, aqui, com o objetivo de evidenciar a fragilidade da argumentação, retornar a Montaño (2002, p. 255), para quem "A descentralização administrativa, a privatização e a transferência para o 'terceito setor' das respostas às seqüelas da 'questão social' [...] repercutem negativamente no aumento tendencial do nível de desemprego profissional, na precarização das condições de trabalho".

Em que pesem diferenças de "status" institucional ou de propósitos anunciados, as ONGs e os novos movimentos sociais corroboram o sentido atribuído à sociedade civil tal como concebida pelo pensamento liberal, cujo significado impregna o senso comum. Entretanto, conforme assinala Acanda (2006, p. 174), "[...] o conceito de sociedade civil é uma noção política, não um instrumento neutro". Temos, assim, um esvaziamento da noção de sociedade civil tal como formulada por Gramsci (1999; 2000), que a compreendia como espaço fecundo de disputa por hegemonia, como lócus de materialização das correlações de forças. Pacificada pelo consenso e pela busca da harmonia entre aqueles que são naturalmente diferentes no que concerne às condições de acesso aos bens materiais e simbólicos, a sociedade civil é transformada no espaço do bem, da ajuda mútua e da convergência de interesses. Destituída de seu potencial contra-hegemônico, é, assim, funcionalmente reduzida a peça fundamental para manter a governabilidade num quadro de profundo processo de destituição de direitos.

Ao relacionar esses movimentos com aquilo que denomina de "ONGs operacionais", valendo-se de expressão cunhada pelo Banco Mundial, Petras chama a atenção para o fato de que, no âmbito dos microprojetos em que se envolvem, tais entidades elegem a educação, concebida sob uma ótica restritiva, como fundamental para atingir seus objetivos "apolíticos": "Ante todo, la implementación de proyectos locales requiere un entrenamiento en habilidades específicas, más que una educación general que involucre análisis 
de políticas y procesos socioeconómicos" (PETRAS e VELTMEYER, 2005, p. 41). É precisamente nessa perspectiva redutora e oposta à educação que vise a concorrer para a emancipação humana que se situa a maior parte das ações voltadas para a educação de jovens e adultos na sociedade brasileira.

\section{Conclusão}

Para Mészáros (2002, p. 209, grifos do autor), “[...] a instituição e o aperfeiçoamento da igualdade formal e da desigualdade substantiva pertencem ao modo normal de funcionamento do sistema do capital". É no âmbito desse "modo normal" que se situam as ações empreendidas no campo da educação de jovens e adultos trabalhadores, que em algumas circunstâncias podem, no máximo, chegar a concorrer para a "emancipação política", mas não ensejam condições de "emancipação humana".

É certo que são os próprios trabalhadores que devem construir a auto-emancipação, entretanto tal processo pode ser favorecido ou, como no quadro aqui analisado, ser crivado de obstáculos de diferentes ordens. Restringir as diferentes ações educativas aos limites inerentes à própria origem dos novos movimentos e ao caráter das organizações executoras, tanto de políticas de governo para a educação de jovens e adultos (entre as quais devem ser destacados o Novo PROJOVEM e o Programa Brasil Alfabetizado) quanto de outras ações educativas demandadas por diferentes frações da classe trabalhadora - fragmentadas sob a égide das múltiplas diferenças -, constitui, sem dúvida, um obstáculo a ser superado.

A emancipação humana requer a concomitante construção de uma nova hegemonia, a qual exige a ruptura com a "[...] dimensão totalizante e abrangente do capital, que engloba desde a esfera da produção até o consumo, desde o plano da materialidade ao mundo das idealidades" (ANTUNES, 1995, p. 81).

Nessa perspectiva, a questão da hegemonia nos impõe, necessariamente, recorrer a Gramsci para compreender o fato de que é fundamental que a classe que pretende transformar estruturalmente a sociedade, antes de ser dominante, precisa ser dirigente. Analisando sua própria formação política, construída no movimento do Ordine Nuovo, Gramsci nos oferece 
importantes elementos para a reflexão acerca da emancipação humana como hotizonte para a classe trabalhadora.

Acerca da direção política daquela época e das relações pedagógicas nela implícitas, ele afirma:

Essa direção não era "abstrata", ela não consistia em repetir mecanicamente fórmulas científicas ou teóricas, ela não confundia a política da ação real com a pesquisa particular do teórico; ela se aplicava a homens reais, que haviam sido formados em condições determinadas, com sentimentos, modos de ver, fragmentos de concepção de mundo determinados, que resultavam de combinações "espontâneas" de um certo meio de produção material com a "fortuita" aglomeração de elementos sociais díspares. Esse elemento de "espontaneidade" não foi negligenciado, menos ainda desprezado: ele foi educado. (GRAMSCI [1930] apud BUCI-GLUCKSMANN, 1980, p. 201, grifos do autor)

As ações atualmente em curso, assentadas, de diferentes formas, na lógica dominante, valorizam e exploram modos de ver, fragmentos de concepção de mundo determinados, propiciando àqueles aos quais se destinam a crença no fato de que suas individualidades estão, finalmente, sendo contempladas. Em tal processo, as potencialidades transformadoras, no mais das vezes, perdem-se no âmbito das ações imediatas e fenomênicas. Além disso, ficam restritas à prévia demarcação imposta pela lógica do sistema do capital.

Por outro lado, porque permanentemente marcado pela contradição - categoria estruturante do materialismo histórico -, o processo sóciohistórico, em sua riqueza nem sempre apreendida na plenitude de suas potencialidades, abriga iniciativas de diferentes frações da classe trabalhadora que apontam para a construção de processos pedagógicos comprometidos com a emancipação humana. Neles, se evidenciam possibilidades concretas de construção de propostas educacionais comprometidas com a formação de "[...] uma sociabilidade de sujeitos autônomos, ainda que no marco capitalista” (OLIVEIRA, 1998, p. 207). 
Os objetivos e limites deste trabalho não permitem que nos debrucemos sobre a análise de tais iniciativas. Entendemos, porém, ser relevante fazer referência a elas com o objetivo de evidenciar, ainda que de forma breve, as possibilidades de luta contra-hegemônica que emergem dos movimentos sociais efetivamente comprometidos com a mudança estrutural da realidade. Entre tais experiências, elegemos, a título de exemplo, duas vinculadas de diferentes formas às instituições públicas de ensino, sublinhando o fato de que é possível - e necessário - valer-se da estrutura do Estado, configurando-o de outro modo, a partir das disputas inerentes a todos os processos de correlações de forças que marcam as lutas por hegemonia.

Destacamos, assim, em primeiro lugar, o Projeto de Educação de Trabalhadores (PET), concebido e executado pela Escola Sindical 7 de Outubro, vinculada à Central Única dos Trabalhadores. Essa iniciativa apresentou como singularidade o fato de ter sido concebida por uma central sindical e implementada na Rede Pública Municipal de Educação de Belo Horizonte, com o claro objetivo de empreender disputas teórico-metodológicas no âmbito da educação de jovens e adultos trabalhadores e, de forma mais abrangente, disputar no âmbito do próprio Estado uma concepção de política pública de educação da classe trabalhadora centrada no princípio educativo do trabalho para além de sua subordinação à lógica capitalista. O período de referência para nossos estudos vai de 1991, quando de sua concepção, passando por 1995 , ano de formação da primeira turma, até o ano 2000 , a partir de quando o PET sofre um deslocamento dos princípios ético-políticos fundadores, passando a incorporar uma concepção pedagógica baseada numa lógica fragmentada e fragmentária. Tal deslocamento, bem como a própria extinção do Projeto, configuram, segundo nosso entendimento, a explicitação da importância pedagógica das tensões que marcam os processos de correlações de forças entre a lógica da ordem e a que norteia as ações ancoradas na luta contra-hegemônica. Ao deixar-se capturar pelo discurso da ordem presente nas práticas transformistas (GRAMSCI, 2000), o PET perdeu o vigor e, subsumido, perdeu, também, sua razão de ser.

Também não podemos deixar de mencionar a importante contribuição teórico-prática do Movimento dos Trabalhadores Sem Terra - MST para a educação da classe trabalhadora brasileira. Esse movimento social tem reconhecida importância, cuja projeção nas duas últimas décadas 
se apresenta como claro exemplo de disputa contra-hegemônica que se expressa em diversos campos, entre eles o educacional. É bastante amplo o arco de ações educativas empreendido pelo movimento, que envolve desde o trabalho com os Sem-Terrinha, nas escolas itinerantes dos acampamentos e nas escolas dos assentamentos, até diferentes cursos de formação técnicoprofissional, como os oferecidos na Escola Nacional Florestan Fernandes e, ainda, cursos de nível superior nas áreas de Administração e Gestão, Direito, Geografia, História e Letras, oferecidos aos militantes em universidades conveniadas (em sua maioria, públicas). A atuação do MST no âmbito da educação evidencia o fato de que é possivel conceber e implementar propostas político-pedagógicas marcadas pela perspectiva de educação integral como direito da classe trabalhadora.

Para melhor explicitar o que se pretende aqui ressaltar, valemo-nos de Caldart (2005), do Setor de Educação do MST, que destaca:

Em dados estimados podemos dizer que o MST conquistou em 20 anos aproximadamente 1.500 escolas públicas nos seus acampamentos e assentamentos, colocando nelas em torno de 160 mil crianças e adolescentes Sem Terra, e ajudando a formar os seus mais de 4 mil educadores; também desencadeou um trabalho de alfabetização de jovens e adultos, envolvendo entre 2003 e 2004 mais de 30 mil educandos e 2.000 educadores; começou a desenvolver práticas de educação infantil em seus cursos, encontros, acampamentos e assentamentos, que formam pelo menos 500 educadores nesta nova frente; conseguiu criar algumas escolas de ensino médio nos assentamentos e fazer cursos superiores em parceria com diferentes universidades brasileiras.

Caldart (2005) assinala, ainda, que 17 anos de luta foram necessários para a concretização das Escolas Itinerantes dos Acampamentos, que contam com “[...] um tipo de estrutura e proposta pedagógica criada especialmente para acolher as crianças e os adolescentes do povo Sem Terra em movimento". Essas escolas e as demais iniciativas educacionais do MST tomam como princípio ético-político e pedagógico a premissa de que "[...] é a escola que deve ajustar-se, em sua forma e conteúdo, aos sujeitos que 
dela necessitam; é a escola que deve ir ao encontro dos educandos, e não o contrário" (CALDART, 2005).

Os exemplos aqui apresentados brevemente constituem distintas formas de materialização de orientações fundamentais que nos são oferecidas por Marx acerca da educação de classe trabalhadora. Essa educação, que não pode deixar de ser integral, exige, para sua efetiva constituição, intensa mobilização dos trabalhadores. Somente essa intensa mobilização pode tornar concreta a indicação que Marx (1980b) nos apresenta na Critica ao Programa de Gotha, quando sublinha que cabe ao Estado cumprir as suas obrigações e as funções de assegurar todas as condições para a educação do povo, mas o Estado não pode ser designado, pelo povo, como seu educador.

Trata-se, portanto, de tomar como premissa o fato de que, na construção da contra-hegemonia, impõe-se "[...] uma autopedagogia capaz de unir teoria e prática e de levar adiante uma reforma intelectual e moral em diálogo com a classe que vive do próprio trabalho" (LEHER, 2005, p. 10). Esse processo exige a superação da tutela à qual está, de formas diferenciadas, submetida a maior parte da sociedade. Nesse sentido, cabe interrogar em que medida as novas mobilizações centradas, estritamente, em particularidades e em exigências pertinentes, mas pontuais, rompem com a lógica totalizante do capital, que se esconde sob a aparência da valorização da diversidade, ela própria transformada em mercadoria.

Impõe-se, assim, recusar as armadilhas do novo ou moderno, assentadas, na realidade, em perspectivas conservadoras, desviando a luta daquilo que constituiria uma conquista concretamente nova, centrada numa " [...] agenda educacional radicalmente moderna, republicana, laica" (LEHER, 2000, p. 171). Se é inegável que a educação, no modo de produção capitalista, está subsumida à "desigualdade substantiva", que lhe é inerente e da qual nos fala Mészáros (2007), não menos verdadeira é a importância de que aqueles que consideram necessária, não somente a melhoria das condições de vida, mas a possibilidade de uma vida igualmente digna para todos, portanto, de um novo projeto societário, defendam um projeto educacional que não se restrinja a motivações particularistas centradas em formas inovadoras de filantropia e de assistência, e em interesses regulados pelas demandas do mercado. Mais uma vez recorrendo a Leher (2005, p. 10), consideramos necessário chamar a atenção para o fato de que o conformismo, em suas 
variações, "[...] ainda que edulcorado com um discurso social, nada pode oferecer senão o rastro de destruição provocado pelo capitalismo realmente existente".

\section{Notas}

1 Neste artigo, são apresentados resultados parciais de pesquisas que vimos empreendendo, na última década, com apoio financeiro do CNPq.

2 Segundo Pochmann (2005, p. 50), a precarização das condições de trabalho atingia 55,7\% da PEA em 1940, índice reduzido para $34,1 \%$ em 1980 e elevado a 40,4\% em 2000.

3 Em outras traduções, como por exemplo, as apresentadas em Os economistas (1983), Ospensadores (1978), Marxists Internet Archives (2005), não é utilizada a palavra educafão, a qual pode, entretanto, ser depreendida, por exemplo, da expressão "trabalho qualificado", como utilizada por Marx.

4 É importante assinalar que a expressão "novos movimentos sociais" possui forte matriz européia, sendo atribuída, por muitos autores, a Offe (1988), importante influência em sua formulação. Para ele, tais movimentos, em oposição à antiga classe trabalhadora, emergem a partir da ação de atores sociais como: a nova classe média, especialmente a parte dela que trabalha em profissões de serviços humanos e/ou no setor público; alguns elementos da velha classe média e ainda parte da população formada por pessoas à margem do mercado de trabalho ou em uma posição periférica respectiva a ele.

5 Em 2006, o IBGE, em parceria com o Ministério do Desenvolvimento Social e Combate à Fome (MDS), realizou pesquisa sobre as Entidades de Assistência Social Privadas sem Fins Lucrativos, na qual foram identificadas 33.076 entidades relacionadas ao grupo Assistência Social.

6 Embora o número de ONGs em funcionamento no Brasil não esteja definido, em 2002, estimativas da ABONG e do IBGE informavam acerca de aproximadamente 270 mil instituições filantrópicas ou similares. Há, atualmente, estimativas de que este número tenha praticamente dobrado. 
7 O atual estágio de nossa investigação ainda não permite enunciar ONGs que configuram a tipificação aqui apresentada. Porém, para exemplificar o afirmado, podemos remeter ao caso das ONGs - largamente divulgado pela mídia impressa no ano de 2007 - que, em virtude de irregularidades diversas, entre elas o desvio de recursos públicos no âmbito do Programa Brasil Alfabetizado, concorreu para que o governo federal introduzisse alterações na distribuição das verbas, passando a priorizar as redes públicas de ensino, conforme explicitado no Plano de Desenvolvimento da Educação apresentado pelo Ministério da Educação em abril de 2007.

8 A respeito desse processo, ver análise detalhada em Aguiar (2006).

\section{Referências}

ACANDA, Jorge Luis. Sociedade civil e hegemonia. Rio de Janeiro: Ed. UFRJ, 2006.

ADORNO, Theodor W. Educafão e emancipafão. Rio de Janeiro: Paz e Terra, 1995.

AGUIAR, Lucilia. O Projeto de Educafão dos Trabalbadores - PET e a construção de uma prática educativa em EJA a partir do Movimento Sindical. 2006. Dissertação (Mestrado em Educação) - Programa de Pós-Graduação em Educação da Universidade Federal Fluminense, Niterói.

ANTUNES, Ricardo. Adeus ao trabalho? São Paulo: Cortez, 1995.

ARRIGHI, Giovanni. $A$ ilusão do desenvolvimento. 6. ed. Petrópolis: Vozes, 1997.

BRASIL. Medida provisória $n^{\circ} 411$, de 28 de dezembro de 2007a. Disponível em: <http://www.planalto.gov.br/ccivil_03/_Ato2007-2010/2007/ Mpv/411.htm>. Acesso: nov. 2007.

BRASIL. Ministério da Educação. Secretaria de Educação Profissional e Tecnológica. O que é o PROEJA. Brasília, 2007b. Disponivel em: <http:// portal.mec.gov.br $/ \mathrm{setec} /$ index.php?option $=$ content\&task $=$ view\&id $=695$ \&Itemid=848>. Acesso: jan. 2008. 
BRASIL. Presidência da República. Decreto 5.840, de 13 de julbo de 2006.

Disponível em: <http://www.planalto.gov.br/ccivil_03/_ato20042006/2006/Decreto/D5840.htm>. Acesso: jan. 2007.

BRASIL. Radiobrás. Agência Brasil. Novo PROJOVEM vai abrir mais 4 milhões de vagas. Brasilia, 2007c. Disponível em: <http://www.agenciabrasil. gov.br/noticias/2007/09/04/materia.2007-09-04.3399417161/view>. Acesso em: fev. 2008.

Presidência da República. Decreto 5.154 de julbo de 2004. Disponivel em: < http://www.planalto.gov.br/ccivil_03/_ato2004-2006/2004/ Decreto/D5154.htm>. Acesso: fev. 2007.

BUARQUE, Cristina; VAINSENCHER, Semira. ONGs no Brasile a questão de gênero. Trabalhos para Discussão, Pernambuco, n. 123, 2001.Fundação Joaquim Nabuco: novembro de 2001. Disponivel em: < http://www. fundaj.gov.br/tpd/123.html>. Acesso em set. 2007.

BUCI-GLUCKSMANN, Christinne. Gramsci e o Estado. São Paulo: Paz e Terra, 1980.

CALDART, Roseli Salete. O lugar da escola na pedagogia do MST. In: EDUCAÇÃO pública: biblioteca. Rio de Janeiro: CECIERJ, 2005. Disponivel em: <http: //www. educacaopublica.rj. gov.br/biblioteca/ educacao/0070.html> .Acesso em: dez. 2006.

CAMPAGNAC, Vanessa. As organizações não governamentais (ONGS) e o mercado de trabalho. In: ENCONTRO NACIONAL DE ESTUDOS POPULACIONAIS, 15., 2006. Caxambu. Anais eletrônicos... Caxambu Disponivel em: <http://www. abep.nepo. unicamp.br/ encontro2006 /docspdf/ABEP2006_224.pdf>. Acesso em: ago. 2007.

CASTRO, Ramon Peña. Tecnologia, trabalho e educação. Cadernos ANPEd, Caxambu: ANPEd, 1994. 16² Reunião Anual da ANPEd.

FILGUEIRAS, Luiz; GONÇALVES, Reinaldo. A economia politica do governo Lula. Rio de Janeiro: Contraponto, 2007.

FRIGOTTO, Gaudêncio. Fundamentos científicos e técnicos da relação trabalho e educação no Brasil hoje. In: LIMA, Júlio; NEVES, Lúcia.

Fundamentos da educafão escolar do Brasil contemporâneo. Rio de Janeiro: FIOCRUZ, 2006. 
GRAMSCI, Antonio. Cadernos do cárcere: introdução ao estudo da Filosofra: a filosofia de Benedetto Croce. Rio de Janeiro: Civilização Brasileira, 1999. v. 1.

GRAMSCI, Antonio. Cadernos do cárcere: Maquiavel: notas sobre o Estado e a política. Rio de Janeiro: Civilização Brasileira, 2000. v. 3.

HOBSBAWM, Eric. $A$ era das revoluções: 1789-1848. 7. ed. Rio de Janeiro: Paz e Terra, 1989.

KOSIK, Karel. Dialética do concreto. Rio de Janeiro: Paz e Terra, 1978.

KUENZER, Acácia. As relajões entre trabalho e educafão no regime de acumulação flexivel: apontamentos para discutir categorias políticas. Caxambu: ANPEd, 2007. Mimeografado.

LEHER, Roberto. Tempo, autonomia, sociedade civil e esfera pública: uma introdução ao debate a propósito dos novos movimentos sociais na educação. In: GENTILI, P.; FRIGOTTO, G (Org.). A cidadania negada: políticas de exclusão na educação e no trabalho. Buenos Aires: CLACSO, 2000.

LEHER, Roberto. Resgatar a tradição crítica para construir práticas necessariamente renovadas. In: LEHER, Roberto; SETÚBAL, Mariana. (Org.). Pensamento crítico e movimentos sociais. diálogos para uma nova práxis. São Paulo: Cortez, 2005.

LEHER, Roberto; SETÚBAL, Mariana. (Org.). Pensamento critico e movimentos sociais. diálogos para uma nova práxis. São Paulo: Cortez, 2005a.

MARX, Karl. A questão judaica. In: MARX, Karl. Manuscritos econômicofilosóficos. Lisboa: Edições 70, 1989. p. 35-76.

. O processo global da produção capitalista. In: O capital: crítica da economia política. São Paulo: Abril Cultural, 1983. v.3. p. 5-318.

O processo de produção do capital. In: O capital: crítica da economia política. Rio de Janeiro: Civilização Brasileira, 1980a. v.1. p. 4-297.

MARX, Karl. Observações à margem do Programa do Partido Operário Alemão: crítica ao Programa de Gotha. In: ; ENGELS, Fridrich. Obras escolbidas. São Paulo: Alfa-Omega. 1980b. Marxists Internet 
Archives. Disponível em <http://www.marxists.org/archive/marx/>. Acesso: ago.2007.

MENDONÇA, Sonia Regina; FONTES, Virgínia. História do Brasil recente: 1964-1980. 2. ed. São Paulo: Ática, 1991.

MÉSZÁROS, István. Para além do capital. São Paulo: Boitempo, 2002.

MÉSZÁROS, István. A educação para além do capital. In: MÉSZÁROS, István. O desafio e o fardo do tempo bistórico: o socialismo no século XXI. São Paulo: Boitempo, 2007.

MONTAÑO, Carlos. Terceiro setor e questão social: crítica ao padrão emergente de intervenção social. São Paulo: Cortez, 2002.

OFFE, Claus. Partidos politicos y nuevos movimientos sociales. Madrid: Sistema, 1988.

OLIVEIRA, Francisco. A vanguarda do atraso e o atraso da vanguarda. In: OLIVEIRA, Francisco . Os direitos do antivalor: a economia política da hegemonia imperfeita. Petrópolis: Vozes, 1998.

PETRAS, James; VELTMEYER, Henry. Movimientos sociales y poder estatal. Argentina: Lumen, 2005.

POCHMANN, Marcio et.al. (Org.). Agenda não liberal da inclusão social no Brasil. São Paulo: Cortez, 2005.

PUIGGRÓS, Adriana. La fábrica del conocimiento: los saberes socialmente productivos en América Latina. Rosario: Homo Sapiens, 2004.

RUMMERT, Sonia Maria. Educação de adultos, trabalho e processos de globalização. Contexto e Educação, Ijuí / RS, 9, 39, p. 89-111.

. Educaf̧ão e identidade dos trabalbadores: as concepções do capital e do trabalho. São Paulo: Xamã, 2000.

Programa Integração: avanços e contradições de uma proposta de educação formulada por trabalhadores. Revista Brasileira de Educafãa, Rio de Janeiro, v. 27, p. 138-153, 2004.

RUMMERT, Sonia Maria. Projeto Escola de Fábrica: atendendo a pobres e desvalidos da sorte do século XXI. Perspectiva, Florianópolis, v. 23, n. 2, p. 303-322, 2005. 
RUMMERT, Sonia Maria. Historiografia da educação de jovens e adultos trabalhadores e a naturalização do caráter dual da educação brasileira. In: MENDONÇA, Sonia Regina de. (Org.). Estado e bistória no Brasil. Niterói, R.J: EdUFF/ FAPERJ, 2006. p. 145-159.

Movimento sindical e políticas públicas para a educação da classe trabalhadora no Brasil. In: CANÁRIO, Rui (Org.). Educafãa popular e movimentos sociais. Lisboa: EDUCA, 2007a. v. 2, p. 81-106.

RUMMERT, Sonia Maria A educação de jovens e adultos trabalhadores: o "novo" que reitera antiga destituição de direitos. Sisifo, Revista de Ciências da Educação, v. 2, 2007b. Disponível em: < http://sisifo.fpce. ul.pt/>. Acesso em: 10 jun. 2007. 


\section{Education of Young and Adult Workers in Brazil today: from simulacrum to emancipation}

\section{Abstract:}

The education of young and adult workers in Brazil today has received special attention in federal government policies. Beyond the apparent "democratization" of opportunities for greater education, and above all, of access to scientific and technological knowledge, this process includes functionalities that must be analyzed. Some of the principal socio-economic factors of the current government actions to raise the educational levels of the working class are analyzed, considering the current social division of labor in Brazilian society. The relations that social movements establish with these policies will also be addressed. They may be aimed at a search for emancipation, which is built by exploring the contradictory character of the reality, while they may also be marked by an acritical and conformist adhesion to the programs. An understanding of these complex processes requires that distinctions be established among the so called traditional social movement and the new social movement, which is another objective of this work.

Key words: Education of young and adult workers. Labor and Education. Emancipation-social movements.
Éducation de jeunes et d'adultes travailleurs au Brésil aujourd hui: du simulacre à l'émancipation

\section{Résumé:}

Léducation des jeunes et d'adultes travailleus réçoit, actuellement au Brésil, spécial attention au plan des politiques du Gouvernement Fédéral. Au-delà de l'apparente "démocratisation" des oportunités en envisageant augmenter la scolarité et, surtout, l'accès aux bases de la connaissance scientifique et tecnologique, ce processus a des fonctionnalités quil faut dévoiler. En ayant par but les expliciter, ils seront présentés quelques contraintes sócio-économiques, des actions du gouvernement actuel, que se tournent pour l'élévation de la scolarité des couches travailleuses. Pour cela, on prend comme référence l'actuelle division sociale du travail dans la societé brésilienne. On explicitera, encore, les rélations que les mouvements sociaux établissent avec les actions qui composent la politique du gouvernement. Ces politiques peuvent se tourner ver la quête d'émancipation, celle-ci construite en exploitant le caractère contradictoire du réel, ou être marquées par l'adhésion naïve et conservatrice. Pour comprendre ce processus dans sa complexité, il faut distinguer les "mouvements sociaux traditionnels" des "nouveaux mouvements sociaux". Cela constitue aussi l'objectif de cet article.

Mots-clés: Éducation des jeunes et d'adultes travailleurs. Travail et education. Émancipation - mouvements sociaux. 


\section{Sonia Rummert}

Universidade Federal Fluminense, Centro de Estudos Sociais Aplicados Departamento Sociedade Educação e Conhecimento

Praça Leoni Ramos s/n - Campus do Gragoatá - Bloco D - Sl. 526

São Domingos - CEP: 24210-200

Rio de Janeiro - RJ

E-mail: rummert@uol.com.br

Recebido em: 13/5/2008

Aprovado em: 17/8/2008 